\title{
Pain and ketoprofen: what is its role in clinical practice?
}

\section{Dolore e ketoprofene: quale ruolo nella pratica clinica?}

\author{
P. Sarzi-Puttini ${ }^{1}$, F. Atzeni ${ }^{1}$, L. Lanata ${ }^{2}$, M. Bagnasco ${ }^{2}$, M. Colombo ${ }^{3}$ F. Fischer ${ }^{3}$, M. D'Imporzano ${ }^{3}$ \\ ${ }^{1}$ Rheumatology Unit, L. Sacco University Hospital, Milan, Italy; \\ ${ }^{2}$ Dompé SpA, Milan, Italy; \\ ${ }^{3}$ U.O.C. III Division of Orthopaedics and Trauma, G. Pini Orthopaedic Institute, Milan, Italy
}

\begin{abstract}
RIASSUNTO
Questo studio analizza le principali evidenze scientifiche relative a ketoprofene, farmaco anti-infiammatorio non steroideo, nel trattamento del dolore acuto, cronico e post-operatorio. Nei pazienti con dolore di origine reumatica e post-traumatica, ketoprofene si è dimostrato efficace e ben tollerato, anche negli anziani. Nel trattamento del dolore post-operatorio, ketoprofene presenta in alcuni studi un'efficacia simile agli oppioidi, con possibile beneficio anche nella prevenzione delle calcificazioni eterotopiche conseguenti a interventi di chirurgia ortopedica maggiore, senza interazioni con i processi riparativi dell'osso. In conclusione, ketoprofene rappresenta una valida opzione terapeutica nel trattamento del dolore di natura reumatica e traumatica e del dolore post-operatorio.
\end{abstract}

Reumatismo, 2010; 62(3):172-188

\section{INTRODUCTION}

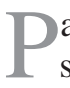
atients fear pain because it causes considerable suffering, and clinicians may not handle it appropriately because they fail to understand it (1). The International Association for the Study of Pain (IASP) defines it as “... is an unpleasant sensory and emotional experience associated with actual or potential tissue damage, or described in terms of such damage" (2). Individual patients perceive it differently, depending on the context of the stimulus, their previous experience, and their current psychological and physical condition. Furthermore, painful stimuli cannot be ignored, disturb behavioural and cognitive activities, and give rise to anxiety and/or depression $(3,4)$.

Acute pain is one of the most frequent reasons for consulting a doctor in all parts of the world (5), and is often associated with already distressing situa-

\section{Indirizzo per la corrispondenza:}

Dr. Piercarlo Sarzi-Puttini

Head of the Rheumatology Unit

L. Sacco University Hospital,

Via G.B. Grassi, 74 - 20157 Milano

E-mail: sarzi@tiscali.it tions such as emergency and elective surgery, severe medical diseases, traumas, childbirth, burns, natural disasters, war and torture. Relieving pain is hampered by political conflicts, social disruption and limited analgesic supplies in many places and, although a number of developed countries have introduced acute pain teams, pain relief is still insufficient in a number of medical settings (6). The 1995 SUPPORT study found that one-half of the patients with life-limiting diseases experienced moderate to severe pain during their last days (7), and subsequent studies have shown that $40 \%$ of postoperative patients report moderate or severe pain, and inadequate pain relief $(8,9)$.

Chronic pain has been defined by the American Society of Interventional Pain Physicians (ASIPP) as "pain that persists six months after an injury and beyond the usual course of an acute disease or a reasonable time for a comparable injury to heal, that is associated with chronic pathologic processes that cause continuous or intermittent pain for months or years that may continue in the presence or absence of demonstrable pathology; may not be amenable to routine pain control methods; and healing may never occur" (10). The many clinical 
conditions characterised by chronic pain are generally described on the basis of the site (e.g. back, head, viscera) and type of injury (e.g. neuropathic, arthritic, cancer, myofascial, diabetic). In particular, neuropathic pain develops as a result of lesions or disease affecting the somatosensory nervous system either in the periphery or centrally. Neuropathic pain is characterized by spontaneous ongoing or shooting pain and evoked amplified pain responses after noxious or non-noxious stimuli (11). Another group of syndromes are classified as central sensitivity syndromes or functional somatic syndromes or medically unexplained clinical conditions (fibromyalgia, irritable bowel syndrome, chronic fatigue syndrome, migraine headache, chronic back pain); they frequently overlap and give rise to different pain localizations (12). This suggests that modulating pain-related information may be related to the onset and/or maintenance of chronic pain: the best example is possibly fibromyalgia because it is very difficult to determine the type of injured tissue, and the degree of musculoskeletal pain, fatigue and sleep alterations differs widely among patients and may be masked by sometimes numerous other symptoms (13).

A number of physiological mechanisms may cause injuries to give rise to nociceptive responses and ultimately pain (14). In response to painful stimuli, action potentials are transmitted by sensory fibres to the cell bodies of the corresponding primary sensory neurons in the dorsal root ganglia (DRG). The most important peripheral nerve fibres are the A and $\mathrm{C}$ primary sensory afferent fibres, which carry pain signals from peripheral mechanical, thermal and chemical stimuli, and reach spinal neurons as a result of synaptic transmission within the dorsal horn of the spinal cord. Many neurotransmitters (glutamate, substance P, etc.) modulate post-synaptic responses and induce further transmission to supraspinal sites (the thalamus, the anterior cingulated cortex, the insular cortex, and the somatosensory cortex) via the ascending pathways (15). The extended or intense dorsal horn neuron activity caused by repeated or sustained stimulation may then increase neuronal responsiveness (14). In the case of peripheral sensitisation, heightened neuron excitability occurs where the pain impulse originates whereas, in the case of central sensitisation, it occurs in the spinal neurons. The repeated stimulation of certain spinal neurons causes them to fire more frequently, thus intensifying the pain and making it last much longer than the stimulus itself. Increased nociception to normally in- nocuous stimuli such as a light touch (allodynia) or an excessive painful response to a painful stimulus such as a pinprick (hyperalgesia) involve plasticity by altering multiple neurotransmitters and intracellular signalling events in the spinal cord dorsal horn (SCDH) neurons (16).

The pain due to sensitisation does not only come from the site of injury, but also from neural messages or impulses. Nerve damage can lead to neuropathic pain, which lasts much longer than the injury itself, greatly exceeds a "normal" response to a painful stimulus, and may also spread to other parts of the body. This process plays a major role in the development of chronic pain.

The spinal cord mechanism of pain amplification is transmitted to the nociceptive neurons in the dorsal horn through unmyelinated $\mathrm{C}$ fibres. The $\mathrm{N}$ methyl-D-aspartate (NMDA) receptors of secondorder neurons are activated during the course of the $\mathrm{C}$-fibre transmission of stimuli. This induces calcium entry into dorsal horn neurons (14), which activates nitric oxide (NO) synthase and leads to NO synthesis. NO can affect nociceptor terminals and enhance the release of sensory neuropeptides (particularly substance P) from presynaptic neurons, which contributes to the development of hyperalgesia and the maintenance of central sensitisation (14).

The presence of several pain inhibitory and facilitatory centers in the brainstem is well recognized. The dorsolateral funiculus appears to be a preferred pathway for descending pain inhibitory systems. Disruption of one or more of the elements of the inhibitory system can result in the equivalent of central sensitization (14).

A variety of different mediators may play a role in the pain system. For example, increasing evidence has provided better understanding of the roles of both immune and pro-inflammatory mediators such as the eicosanoids, bradykinins, serotonin, ATP/ADP, neurotrophins, cytokines, chemokines, and reactive oxygen species (17). These mediators are not exclusive to cells of immune/inflammatory origin, but they are also produced by Schwann cells and spinal glial cells, thereby potentially mediating the mechanism of neuropathic pain. Mitogen-activated protein kinases (MAPKs) family are important for intracellular signal transduction and play critical roles in regulating neural plasticity and inflammatory responses. Accumulating evidence shows that all MAPK pathways contribute to pain sensitization after tissue and nerve injury via distinct molecular and cellular mechanisms (18). The 
discovery that glial activation plays a critical role in modulating neuronal functions and affects the spinal processing of nociceptive signalling has led to new insights into the mechanisms underlying the central sensitisation involved in chronic pain facilitation. Spinal glial activation is a major contributor to the development and maintenance of allodynia and hyperalgesia in various models of chronic pain, including neuropathic pain and the pain associated with peripheral inflammation, and is also involved in some forms of visceral hyperalgesia. Development of specific inhibitors which will modulate mediators targeting neurons and glial cells may lead to new therapies for pain management (18).

Some cognitive styles and personality traits, such as somatisation, catastrophising and hypervigilance, have been associated with the amplification and extent of pain even in the absence of tissue damage (19). Behavioural and cognitive therapies may therefore also effect synaptic transmission in the spinal cord via the descending pathways, and thus prevent or reverse long-term changes in synaptic strength in the pain pathways.

Pain is a leading cause of morbidity worldwide, with published data showing its prevalence as high as $50 \%$ for chronic pain in the European population. This prevalence is likely to continue to rise, particularly in elderly people with comorbid conditions and pain of complex etiologies. There is thus a rapidly growing demand for safe and effective pain management. Adequate and appropriate pain assessment in the clinic is an important prerequisite in formulating a pain management plan, although there is considerable evidence that this is often not done outside the specialist setting.

Management of mild-to-moderate pain has traditionally been based upon the use of non-steroidal anti-inflammatory drugs (NSAIDs) and the synthetic non-opioid analgesic paracetamol (acetaminophen). Both NSAIDs and paracetamol are effective, widely recommended and extensively used. On the other hand, selective cyclooxygenase-2 (COX-2) inhibitors were developed to reduce gastrointestinal side effects and complications, but large-scale studies have highlighted an even more serious potential effect: cardiovascular events. Both the European Medicines Agency (EMA) and the Food and Drugs Administration (FDA) in the US have issued advice to apply cautions and restrictions when prescribing COX-2 inhibitors, particularly for patients at increased cardiovascular risk and for long-term use. If pain persists or increas- es, weak opioids, such as codeine, dextropropoxyphene or tramadol, or even strong opioids, such as morphine or fentanyl, can be used in combination with NSAIDs or paracetamol, in order to control pain.

NSAIDs play a major role in the management of pain in acute and chronic rheumatic diseases, as well as post-surgical pain, considering the fact that these drugs, unlike paracetamol, are also able to relieve inflammation associated to these types of pain. The well known gastrointestinal-related side effects from NSAIDs can be reduced by careful attention to dose and duration of therapy, and may be prevented and treated by using appropriate therapy in combination with NSAIDs.

\section{KETOPROFEN LYSINE SALT}

Ketoprofen is a NSAID belonging to the family of propionic derivates, with analgesic, anti-inflammatory and antipyretic properties (20). It represents a racemic mixture, from which only the $\mathrm{S}$-isomer possesses cyclo-oxygenase inhibiting activity, while the R-isomer is far less potent $(21,22)$. Salification of ketoprofen with the lysine amino acid allowed an improvement of the molecules characteristics $(23,24)$. In particular, ketoprofen lysine salt (KLS) has a higher solubility when compared to acid ketoprofen; this characteristic facilitates a more rapid and complete absorption of the active principle, with a high serum peak concentration reached after 15 minutes following oral administration of KLS compared to 60 minutes after ketoprofen administration (Fig. 1) (25-27). This rapid increase in peak plasma concentration of the KLS consequently results in a more rapid pharmacological activity, with an analgesic activity observed only 30 minutes after the first oral administration in a statistically significant modality compared to placebo (28). Moreover, the excellent solubility of KLS in aqueous solution allows the possibility to use injectable preparations with a similar physiological $\mathrm{pH}$ without the need for preservative, possibly reducing irritant reactions and tissue damage at the application site.

The main mechanism of analgesic action of KLS is the inhibition of cyclo-oxygenase and, consequently, decreased production of prostaglandin $\mathrm{E}_{2}$ $\left(\mathrm{PGE}_{2}\right)$. In addition to its effects on cyclo-oxygenase, ketoprofen also inhibits the lipoxygenase pathway of the arachidonic acid cascade (29) leading to a decrease in the synthesis of leukotrienes. 


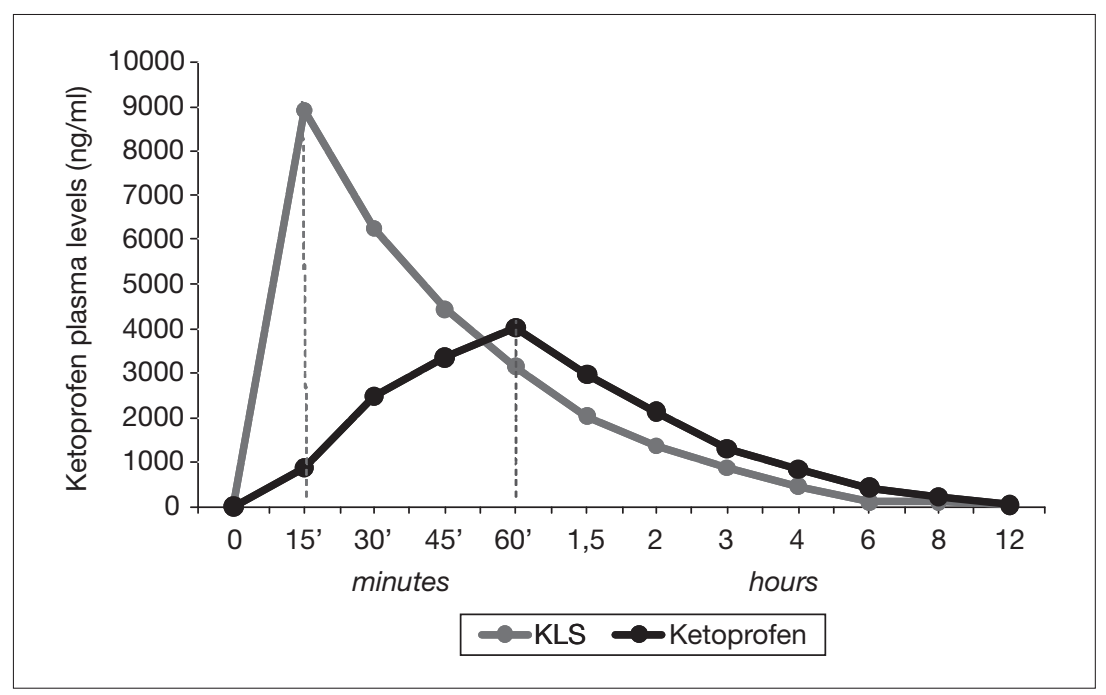

Figure 1 - Ketoprofen plasmatic levels after administration of ketoprofen capsule $50 \mathrm{mg}$ and ketoprofen lysine salt (KLS) sachet or drops $80 \mathrm{mg}(25,26)$.

Interestingly, it has been shown that ketoprofen, as other NSAIDs, has both peripheral and central sites of action (30) through the inhibition of central prostaglandin biosynthesis $(31,32)$, inhibiting both brain cyclo-oxygenase (COX) and nitric oxide synthase. Actually, ketoprofen is rapidly and readily distributed into the central nervous system passing the blood brain barrier within 15 minutes, thanks to its high level of liposolubility (33). It has been recently demonstrated that, besides the inhibition of prostaglandin synthesis at the central level, ketoprofen interacts with the 5-HT system, thus leading to the hypothesis that this characteristic may explain the higher efficacy observed versus other NSAIDs $(22,30,34)$.

These properties make ketoprofen a suitable choice for the management of symptoms associated with musculoskeletal inflammation in both acute and chronic settings (35). It is a highly potent and highly effective NSAID in relieving pain from traumatic, orthopaedic and rheumatic disorders because of its anti-inflammatory and analgesic properties (36).

\section{KETOPROFEN IN CHRONIC RHEUMATIC DISORDERS}

\section{Osteoarthritis}

Osteoarthritis (OA) is a common disorder of the synovial joints. It is pathologically characterised by focal areas of damage of the articular cartilage, centred on load-bearing areas, associated with new bone formation at the joint margins (osteophytosis), changes in the subchondral bone, variable degrees of mild synovitis, and thickening of the joint capsule (37-39). OA is strongly age-related, being less common before 40 years, but rising in frequency with age, such that most people older than 70 years have radiological evidence of osteoarthritis in some joints. The clinical problems associated with these pathological and radiographic changes include joint pain related to use, short-lasting inactivity stiffness of joints, pain on movement with a restricted range, and cracking of joints (crepitus) (4042). However, the severity of joint disease is only weakly related to that of the clinical problem. Recent evidence indicates that peripheral pain sensitisation is a feature of the osteoarthritic joint, perhaps mediated by nerve growth factors or cytokines (38). In addition to peripheral pain sensitisation, central pain sensitisation at the spinal or cortical level can occur in OA (43). Finally, the experience of pain will be modulated by psychological, social, and other contextual factors. Pain in OA, therefore, could be due to local and central sensitisation of pain pathways resulting in normal stimuli becoming painful (43). For these reasons all patients should be educated and treated with exercise, but if these measures fail, NSAIDs, physiotherapy, and the use of aids and appliances should be considered very early.

In an open-label randomised trial conducted in 113 patients with symptomatic hip osteoarthritis, a 4week treatment with either oral ketoprofen or indomethacin showed a significant efficacy of these drugs in relieving osteoarticular pain, stiffness and in improving quality of life. It is worth noting that ketoprofen resulted in a much better safety profile compared to indomethacin, with a lower number of 
patients with adverse reactions or that withdrew from the treatment (44).

Efficacy of oral treatment with KLS has been demonstrated with a significant improvement of pain $(\mathrm{p}<0.01)$ in patients suffering from OA, with a favourable clinical outcome $67.6 \%$ of patients (45).

Moreover, analgesic efficacy of acute oral administration of KLS has been shown to be greater than that of acetylsalicylic acid (ASA), with an increased circulating plasma levels of beta-endorphin and decreased levels of substance P. These data suggest that the rapidly acting and continuous analgesic activity in OA patients could be related to the effect on beta-endorphin and substance $\mathrm{P}$ levels in circulation (46).

\section{Rheumatoid arthritis}

Rheumatoid arthritis (RA) is a chronic inflammatory disease that primarily affects the peripheral joints and often leads to tissue degradation and the destruction of bone and cartilage (47). It usually presents with pain, stiffness and symmetrical swelling of the small joints of the hands and feet, but may also involve other synovial joints. The incidence of RA is estimated at 4-13 per 100,000 for adult males and 13-36 per 100,000 for adult females. RA has a significant impact on a patient's physical, emotional and social functioning that often occurs very early in the disease. Current therapies target the inflammatory consequences of autoimmune activation with the use of disease modifying antirheumatic drugs (DMARD) such as methotrexate (MTX) and biologic DMARD (47). The early use of effective DMARDs is a key point in patients at risk of developing persistent and erosive arthritis. Intensive treatment such as combination DMARDs plus steroids or biological therapies can induce a high rate of remission, control of radiological progression and provide better outcome than DMARD monotherapy in early RA and should be considered in patients at risk $(48,49)$. Systemic glucocorticoids are effective in the shortterm relief of pain and swelling and should be considered, but mainly as a temporary therapy as part of the DMARD strategy. Analgesics are used to manage pain in all stages of the disease, often in combination with other therapies to control the inflammatory process. NSAIDs have an immediate effect on pain and stiffness, without influencing the disease process. Substantial evidence, including a Cochrane review, indicates that both the classical and cyclo-oxygenase 2 (COX-2) selective
NSAIDs are more effective than simple analgesics in relieving the signs and symptoms of active disease in established RA (50). These compounds should be used as supplementary therapy and for the shortest possible time. Among these drugs, KLS is a NSAID with favourable anti-inflammatory and analgesic properties and good penetration into joint space. In an open study of one week duration including twenty six patients with RA and persistent knee effusion, it was demonstrated that treatment with KLS and naproxen (NX) resulted in a significant improvement in tenderness and fair, but not significant, relief of the other clinical parameters (51). Moreover, synovial prostaglandin 2 (PGE-2) levels significantly decreased with both drugs, with a mild prevalence of KLS compared to NX (62.8\% vs $51.7 \%)$. The overall efficacy and tolerability were similar for both treatments, with KLS being slight superior. The authors concluded that the administration of KLS should be recommended for the symptomatic treatment of RA since this study confirms a favourable analgesic and antiphlogistic activity and a good inhibitory effect of KLS on PG levels into the joint space, even when compared to naproxen.

In another study involving 34 patients with rheumatic diseases (20 of which were suffering from RA), it was observed that oral treatment with KLS resulted in a significant improvement in pain, with a significant decrease in spontaneous pain $(p<0.001)$, tenderness, limitation of function and duration of morning stiffness over a 10-day treatment period in all the patients studied (45). Moreover, in 10 patients with a persistent knee effusion, KLS was also observed to penetrate into the synovial fluid, causing a marked decrease in PGE-2 levels in the rheumatoid knee effusion with a percentage of inhibition of about $73 \%$. These results are particularly important in elderly patients. This population is frequently affected by rheumatic diseases such as OA and RA that are associated with comorbidities, and generally require chronic NSAIDs treatment. This raises the question of long term safety and in this regard, ketoprofen has been extensively studied in this particular population. In particular, a prospective study designed to assess the safety profile of ketoprofen over a 12-month treatment period, including 823 patients over 65 years with OA and RA treated with oral ketoprofen, showed that at the end of the study, 521 patients $(63.3 \%)$ remained on the drug regimen. The study demonstrated that oral ketoprofen is safe for the long-term treatment of elderly arthritic patients, 
showing a high maintenance rate and a safety profile similar to that seen in younger patients (52). Safety of ketoprofen in the elderly was evaluated in a very large scale open study including approximately 20,000 elderly patients ( $>60$ years) suffering from painful rheumatic disorders. Oral ketoprofen given for a 4-week period showed an overall efficacy that was rated excellent/good in $74 \%$ of cases by physicians and a very good risk/benefit ratio in elderly patients compared with the general population (53).

\section{Gout}

Gout is an inflammatory arthritic condition affecting $1-2 \%$ of adults in the industrialised world that occurs when uric acid crystals accumulate in joints or other tissues (54-56). It is a common and increasingly significant cause of acute and chronic disability and impaired quality of life (57). Gout is frequently characterized by recurrent attacks of acute arthritis and sometimes it can lead to chronic arthropathy, tophy depositions, and renal disease. Gout is also associated with a broad range of comorbidities including cardiovascular disease, chronic kidney disease, metabolic syndrome (56). Standard management of acute attacks of gout involves treatment with glucorticoids, NSAIDs and colchicine, which remain the most widely recommended drugs to treat acute attacks $(56,58)$. These treatments should be started immediately to be most effective and in order to reduce the risk for acute gout flare (59-61). Several studies have evaluated the effects of ketoprofen in acute gout, showing that intramuscular or oral administration of ketoprofen for 1 week was effective in inducing a rapid and appreciable pain relief in patients with gouty arthritis $(62,63)$. In a 7 -day multicenter double blind trial of oral ketoprofen versus indomethacin; including fifty-nine patients with acute gouty arthritis, more than $90 \%$ of the patients reported pain relief within the 1st day of treatment. At the end of the study, most patients in both groups were rated as having a marked improvement both by both investigators and self-assessment. Moreover, this study concluded that ketoprofen can be expected to provide relief from pain of acute gouty arthritis within 24 hours with similar efficacy but less neurological side effects than the standard drug indomethacin (64).

\section{KETOPROFEN IN ACUTE RHEUMATIC AND TRAUMATIC DISORDERS:}

Acute rheumatic and traumatic diseases and soft tissue injuries are often characterized by pain, swelling and inflammation. They include sprains, strains to muscles and ligaments, tendonitis and bursitis, such as the common lateral epicondylitis (tennis elbow) and trochanteric bursitis, regional myofascial pain syndromes, with trigger points similar to those of fibromyalgia but in a localized distribution, low back pain and neurovascular entrapment, such as carpal tunnel syndrome and thoracic outlet syndrome.

\section{Soft tissue injuries}

The first treatment for most acute soft tissue injuries (bruises, strains, sprains, tears) is to prevent, stop and reduce swelling $(65,66)$. For more seri-

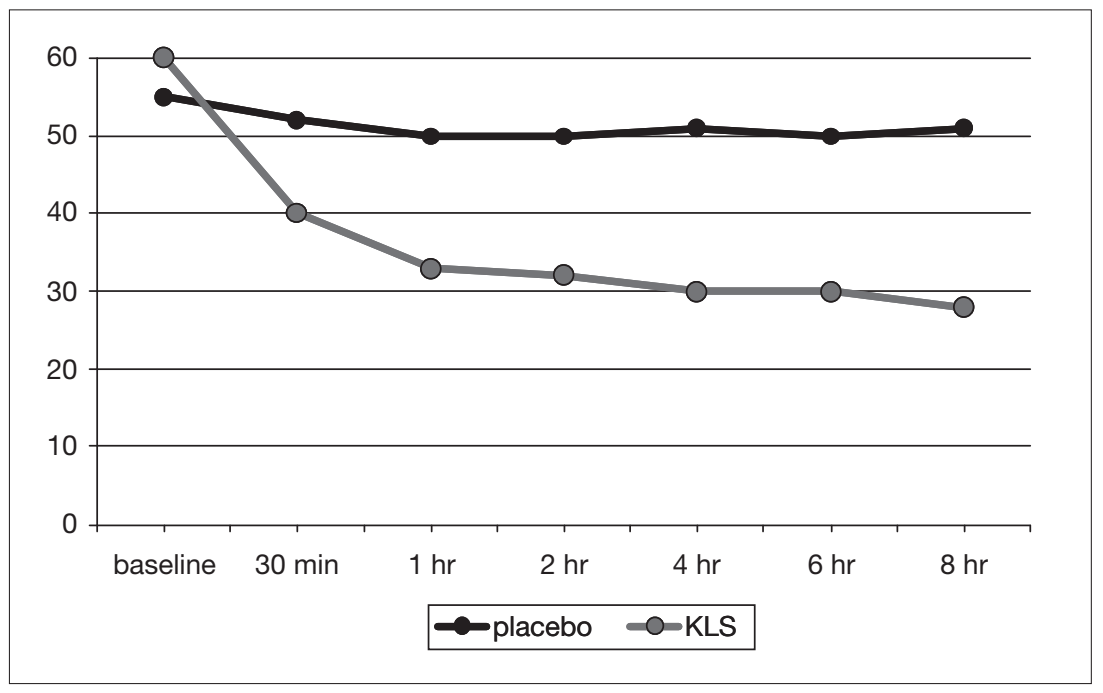

Figure 2 - Analgesic effect on spontaneous pain measured with ScottHuskisson (0-8 hrs) scale after single administration of ketoprofen lysine salt $80 \mathrm{mg}$ and placebo (68). 


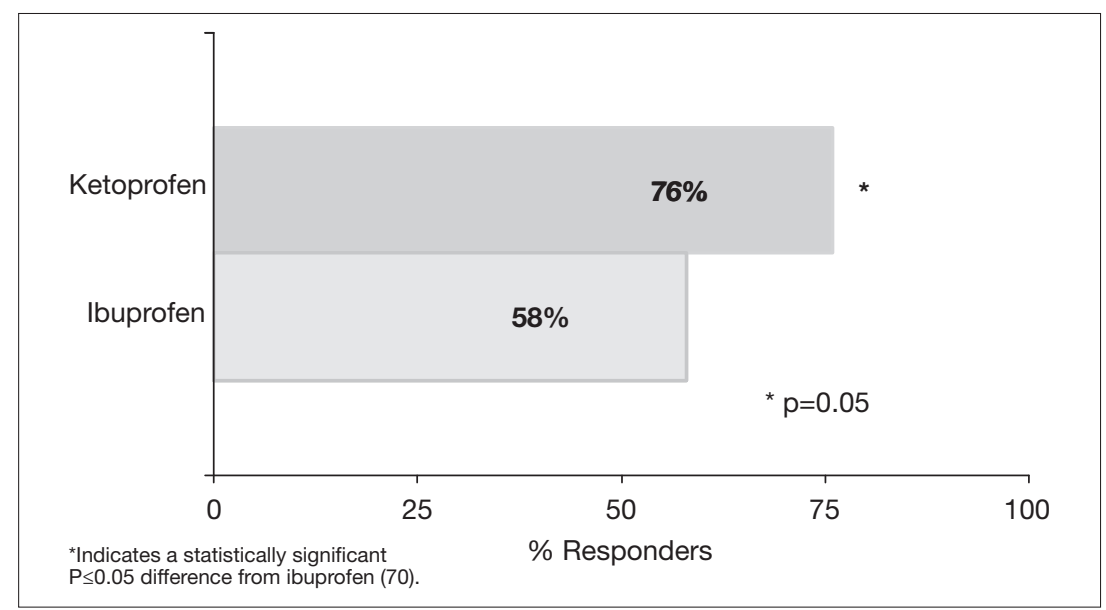

Figure 3 - Patient response to the first dose based on pain relief scores in terms of patients responders $(58 \%$ with ibuprofen $600 \mathrm{mg}$ b.i.d. vs $76 \%$ with ketoprofen 50 mg t.i.d). Responders were defined as patients who had a pain relief score $\geq 50 \%$.

ous overuse injuries, physical therapy, and complete rest associated with NSAIDs may be necessary (67). A randomised, double blind clinical trial of oral KLS (80mg/tid) versus placebo including 120 patients with soft tissue disease as tendinitis, bursitis and periarthritis, showed a significant improvement in pain, tenderness and functional limitation with a rapid and appreciable pain relief. Analgesic activity of KLS was already significant just 30 minutes after treatment (Fig. 2). Moreover, no patient dropped out due to drug related adverse events and was observed to have an excellent safety profile that was identical to that of the placebo group. In conclusion, the study showed that oral KLS is efficacious and safe in patients with soft tissues diseases (68).

Another comparative multi centre study was conducted with the main aim being to evaluate the efficacy and the tolerability of ketoprofen and diclofenac sodium in acute rheumatic and traumatic conditions. One hundred and eighty patients treated with either ketoprofen or diclofenac for 15 days (initially by i.m. injection, then followed by oral administration) showed an improvement in pain symptoms; in particular, the overall complete pain relief of symptoms was observed in $25 \%$ of patients with ketoprofen versus $10 \%$ of patients with diclofenac. Ketoprofen was found to be more effective in providing analgesia in most of the conditions studied in the trial compared to diclofenac, with higher number of patients experiencing complete pain relief. The study also demonstrated a better tolerability profile of ketoprofen versus diclofenac, rated as excellent-good in a higher percentage of patients (69).

An interesting multicenter, double-blind study conducted in 165 patients with sports traumatic pain-related injuries, including tendinitis or tenosynovitis, epicondylitis, traumatic bursitis, sprains or articular contusion, compared the analgesic efficacy of 1-week treatment of ketoprofen $(50 \mathrm{mg} /$ tid per os) versus ibuprofen $(600 \mathrm{mg} /$ bid per os). The results demonstrated that oral ketoprofen had a significantly faster onset of pain relief, by 1.1 hours, than ibuprofen after the first dose and also, produced a strongly higher maximum relief score. Moreover, within 6 hours, $76 \%$ of patients treated with ketoprofen obtained $50 \%$ pain relief (responders) as compared with 58\% of the ibuprofentreated patients $(\mathrm{p}<0.05)$ reaching a greater pain relief in a shorter time compared to ibuprofen (Fig. 3) (70).

\section{Low back pain}

Low back pain is one of the most common conditions encountered in clinical practice and medications are the most commonly used type of treatment. Acute low back pain is usually defined as the duration of an episode of low back pain persisting for less than 6 weeks; sub-acute low back pain as low back pain persisting between 6 and 12 weeks; and chronic low back pain as low back pain persisting for 12 weeks or more. For most patients with low back pain, regardless of the duration of symptoms, paracetamol (acetaminophen) and NSAIDs are the first-line choice for pain relief, as recommended by the APS/ACP and European guidelines (71-73).

A systematic review of randomized trials found that NSAIDs were effective for short-term symptom relief, with an average improvement of about 8 points (on a 0-100 scale) compared with placebo in patients with acute back pain and about 12 points for chronic low back pain (74). Oral and in- 


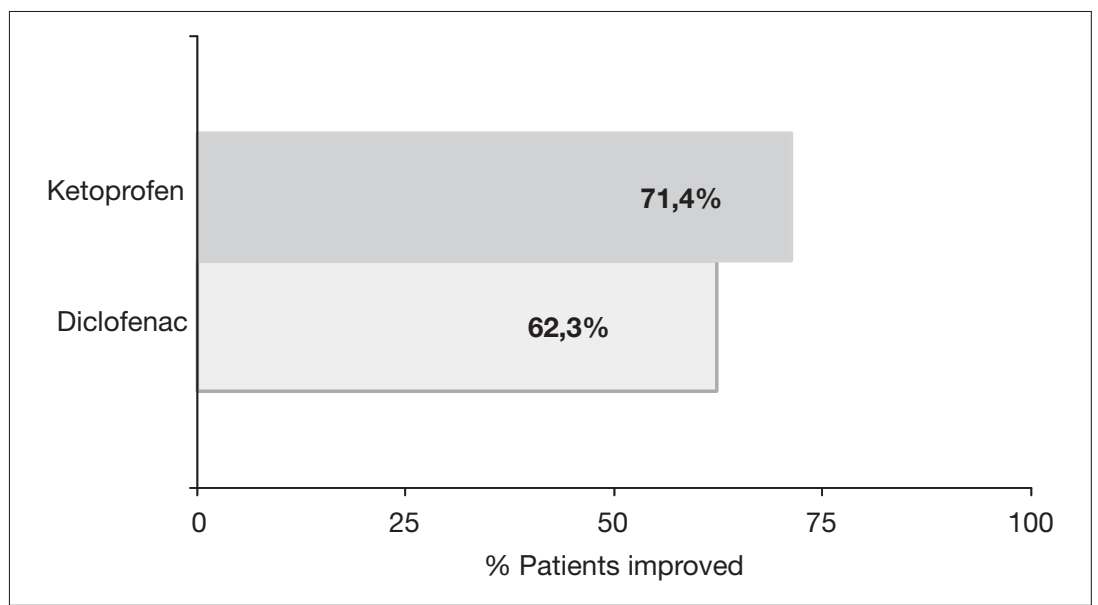

Figure 4 - Overall improvement rate of all symptoms measured as percentage of patients improved, one week after oral administration of either ketoprofen $150 \mathrm{mg} / \mathrm{die}$ or diclofenac $75 \mathrm{mg} / \mathrm{die}$ (76).

tramuscular administration of ketoprofen have been studied in different clinical trials in patients suffering from lumbago. In a comparative 1-week treatment study the efficacy and tolerability of intra-muscular administration of ketoprofen and indomethacin were evaluated in 115 patients with acute low back pain. In this study ketoprofen was shown to significantly reduce global pain with a more sustained improvement compared to indomethacin. Moreover, it is worth noting that a higher percentage of ketoprofen-treated patients experienced pain relief in just 1 hour compared to the indomethacin group (61\% vs $46.9 \%$ ) (75). Another trial involving 155 patients with chronic lumbar pain showed that oral ketoprofen $(150 \mathrm{mg} / \mathrm{die})$ demonstrated higher improvement rates 1 week after administration when compared to diclofenac ( $75 \mathrm{mg} / \mathrm{die})$, and thus, a faster onset of analgesic efficacy $(71.4 \%$ of patients improved vs $62.36 \%$, respectively) (Fig. 4) (76).

\section{KETOPROFEN IN THE POSTOPERATIVE SETTING}

Therapy with NSAIDs is widely used also in orthopaedic clinical practice. They are prescribed in the treatment of osteomuscular pain in both the acute and the chronic phase and provide excellent support in postoperative analgesic therapy.

However, the postoperative period in orthopaedic surgery is not only characterized by the presence of pain, but also by a series of therapeutic interactions, complications, reparative phenomena of the bone and soft tissue and orthopaedic and physiatric prescriptions, with which these drugs may interact.
Opioid drugs are probably recognised as the best drug available in pain management, since they are extremely effective due to their central analgesic action. However, these drugs do cause side effects that are important to be aware of (e.g., respiratory depression, urinary retention, tolerance /dependence, nausea, vomiting and pruritus) which may limit their use and that have led many researchers to seek a viable alternative. NSAIDs, supported by the safe paracetamol and enriched by the introduction of selective COX-2 inhibitors, are in part substituting opioid drugs or, if nothing else, are limiting their use when administered in combination. Among these, ketoprofen has been widely studied in the treatment of postoperative orthopaedic pain in both the acute and the chronic phase. Results are presented with regard to the various possible ways of administration, whether intravenous, intramuscular or oral.

\section{Intravenous administration}

The analgesic efficacy of intravenous ketoprofen was investigated in a study by Castagnera et al. (1988) in 60 patients undergoing orthopaedic surgery detailed as follows: 16 of the spine (disc surgery, spinal stabilization), 15 of the hip (prosthesis and femoral nailing), 15 of the knee (prosthesis, osteotomies, ligament plastics), 14 of the foot and ankle (osteosynthesis or hallux valgus surgery). Patients were treated with ketoprofen (2.5 $\mathrm{mg} / \mathrm{kg}$ ) injected at the onset of pain (T0) (77). Pain was measured by Visual Analogic Scale (VAS) and the Five-Item Verbal Rating Scale (VRS). Results showed a reduction in pain intensity greater than $50 \%$ after 15 minutes and $85 \% 2$ and 3 hours after injection $(\mathrm{p}<0.001)$. Maximum analgesia obtained at 120 minutes in knee and hip surgery and 180 
minutes in the spine and foot/ankle surgery. The duration of analgesic effect was similar between groups ( $8.5 \pm 1.5$ hours). In conclusion, an analgesic effect was observed in $96.6 \%$ of cases, meaning that its analgesic activity combined with its anti-inflammatory effect make the intravenous administration of ketoprofen safe and effective in post-operative pain, reinforcing the consciousness that its antalgic effect is not only due to a peripheral action but also to a central effect.

\section{Intramuscular administration}

In 1992 Manani and colleagues studied 3 groups of patients, each consisting of 25 units, in order to compare the efficacy of intramuscular ketoprofen and naproxen versus placebo in the management of acute postoperative orthopaedic pain in the first 4 hours after the onset of moderate or severe pain (78). If, 2 doses of NSAIDs were not effective, the patient was treated with morphine (10 $\mathrm{mg} \mathrm{im})$. This study showed that ketoprofen more markedly reduces postoperative pain, resulting in a lower demand for additional doses of the same drug and subsequent doses of morphine.

Ketoprofen appeared to be more effective in pain control compared with naproxen for its higher analgesic properties. Naproxen, equipped with more anti-inflammatory properties, may be more favourably used in the treatment of deferred postoperative surgery pain (78).

Efficacy of im administration of ketoprofen was compared with diclofenac sodium, in a study by Shah et al. (2003) (79). One hundred postoperative patients treated with i.m. doses of ketoprofen (100 $\mathrm{mg} / \mathrm{bid})$ or diclofenac $(75 \mathrm{mg} / \mathrm{bid})$ for three days showed an onset of analgesia with each drug within 15-30 minutes; however, ketoprofen was supe- rior to diclofenac in its onset of action, showing an early response (i.e., $15-20$ minutes in $92 \%$ of cases as compared to $84 \%$ of cases with diclofenac) (Fig. 5). This study demonstrated that ketoprofen induced a longer duration of analgesic effect (12 hours) in a higher percentage of cases compared to diclofenac with a lower rate of patients who needed additional doses of opioid, demonstrating that it is a more potent analgesic drug compared to diclofenac.

\section{Oral administration}

More recently, Karvonen and co-workers (2008) conducted an important randomized, double-blind, placebo-controlled study to compare oral paracetamol and ketoprofen in reducing the side effects of opioid analgesics after major orthopaedic surgery (80). Sixty patients were investigated and divided into 3 groups (oral placebo, paracetamol and ketoprofen ) treated immediately after hip prosthesis. After surgery, all patients were provided with a patient-controlled elastomer for administration of $0.05 \mathrm{mg}$ over 5 minutes of intravenous bolus fentanyl. The dose could be repeated at most every 5 minutes with a maximum of $0.3 \mathrm{mg}$ every hour. Pain was measured by VAS, respiratory rate, peripheral arterial saturation, heart rate, blood pressure and side effects were recorded every 4 hours for a total period of 20 hours. Results showed that values of pain were similar in the 2 active groups: patients in the ketoprofen group consumed on average $22 \%$ less fentanyl $(\mathrm{p}<0.05)$ compared with the placebo group and $28 \%$ less than the paracetamol group $(\mathrm{p}<0.05)$. Therefore, oral ketoprofen may decrease the consumption of fentanyl while paracetamol does no affect the consumption of opioids postoperatively. There were no differences be-

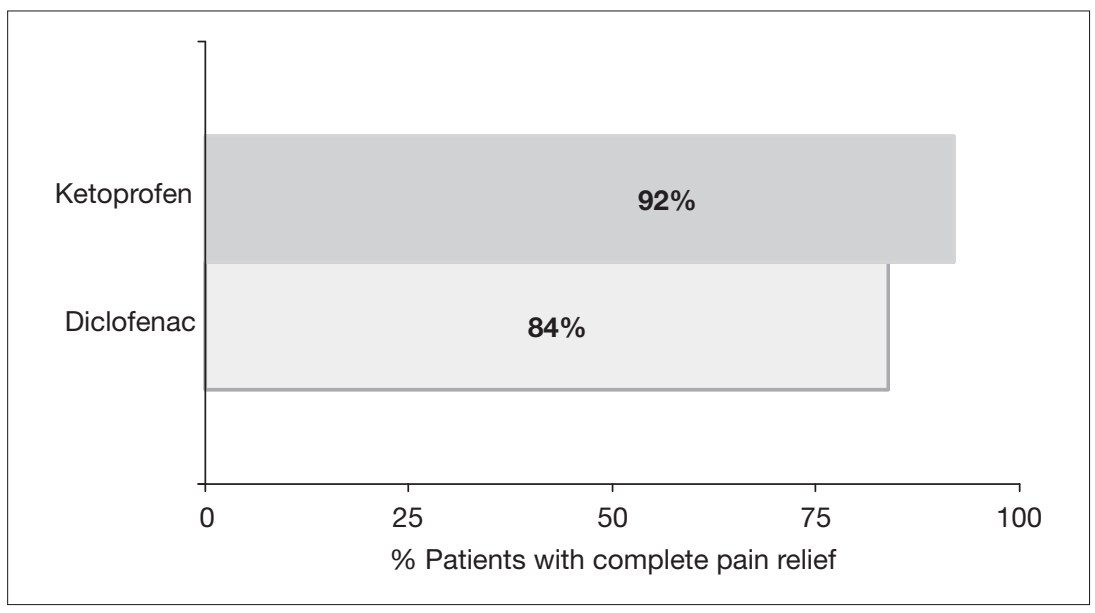

Figure 5 - Onset of analgesia measured as percentage of patients with complete pain relief after 15-20 minutes from the first injection of ketoprofen 100 i.m. or diclofenac 75 i.m. (79). 
tween the 2 groups regarding side effects and patient satisfaction.

\section{Elastomeric devices}

NSAIDs are often used in the immediate postoperative period, in combination with other analgesic drugs in elastomeric infusion devices. These treatments allow a careful management of postoperative pain with extending compliance of the patient.

It is mandatory, however, that such combinations in this context should be safe and stable over time in order to avoid collateral effects or ineffective therapy.

In 2005, Anacardio and colleagues conducted a study to investigate the physicochemical compatibility of ketoprofen lysine salt with other analgesics normally used in combination in elastomers (e.g., tramadol, ketorolac and morphine) (81). Two molecules can be considered pharmacologically compatible when, combined, show no significant changes in their physicochemical properties for the period necessary for their administration. However, many substances, if combined, can lead to changes in their therapeutic properties or to serious side effects. Incompatibility can lead to visible changes: precipitation, turbidity, colour or viscosity changes, effervescence and formation of 2 layers of liquid which cannot be mixed. Chemical degradation phenomena occur, such as hydrolysis, oxidation, reduction, photo-degradation, racemization and epimerization. Compositions also depend on temperature and $\mathrm{pH}$ and are influenced by the concentration of active ingredients, by the exposure to light and by the ionic charge of the solution. Other alterations are not macroscopic and can be analyzed by chromatography. The properties that were investigated are colour, clarity, $\mathrm{pH}$, content of active ingredient, as measured by HPLC method with ultra violet rays before and after 7 days the association that took place at room temperature and under light protection. Physical and chemical parameters were measured immediately, after 12 hours, 1, 2, 7 days. After 7 days there have been no changes in colour, clarity or $\mathrm{pH}$ for all associations evaluated (ketoprofen lysine salt and tramadol, ketoprofen lysine salt and ketorolac, ketoprofen lysine salt and morphine) with a $\mathrm{pH}$ very close to the physiological one, even the combination of ketoprofen lysine salt with morphine, that, alone has a $\mathrm{pH}$ of 4.5. HPLC analysis demonstrated that there was not a decrease of more than $10 \%$ of the nominal content of active ingredient in all three associations. Therefore ketoprofen lysine salt in vials can be used safely in combination in elastomeric infusion devices with tramadol or ketorolac for the period necessary for pain management after orthopaedic surgery.

\section{Ketoprofen versus opioid drugs}

In 1987 Langlais and colleagues performed a study on 59 patients undergoing arthrolysis or knee ligamentoplasty, carpal or foot surgery, whose aim was to compare the efficacy of ketoprofen and pethidine in the treatment of postoperative pain (82). Pain relief obtained was similar in both groups (67\% ketoprofen compared to $63 \%$ pethidine) and also the duration of the effect was almost the same (9.2 hours in the ketoprofen group and 8 hours in the pethidine group). No side effects were reported in patients treated with ketoprofen. These findings suggest that ketoprofen could be considered a good alternative to pethidine, especially after operations on joints that need early mobilization and rehabilitation.

These results were later confirmed by Hommeril and co-workers (1994) thanks to a double-blind study, randomized, which compared the effect of intravenous ketoprofen $(200 \mathrm{mg}$ ), followed by a continuous elastomeric infusion of $12.5 \mathrm{mg} / \mathrm{h}$ for 13 hours, with the extradural administration of morphine $(4 \mathrm{mg})$ in 32 patients undergoing knee and hip prostheses (83). Pain was measured by VAS before surgery, 1 hour later and every 2 hours thereafter. There was an average decrease of pain by $44 \% 1$ hour after administration in the group treated with extradural morphine and $54 \%$ in the ketoprofen group. There were no significant differences between the 2 groups regarding the values of pain reduction and the need for further analgesia. In 3 patients treated with extradural morphine showing hypercapnia, naloxone $(5 \mathrm{mg} / \mathrm{kg} / \mathrm{h})$ was administered as an antidote. In the morphine group, there was an increase in urinary retention. Therefore, analyzing the risk-benefit rate, ketoprofen appears safer than morphine and equally effective in the treatment of pain after intervention of hip or knee prostheses.

\section{Post-surgical calcifications and bone reparative processes}

There are many immediate, late or chronic complications which may develop after orthopaedic surgery. Among these we wish to draw our attention to hip periprosthetic calcification and osteopenia (e.g., Sudeck's atrophy), which can affect any bone segment after prolonged immobilization 
(cast or orthesis) or if deprived of any mechanical stimulus. Hip and pelvis surgery is often complicated $(60 \%)$ by the formation of heterotopic calcification in soft tissues surrounding the operated joint. They may become symptomatic, thus creating serious inconvenience to the patient and interfere with rehabilitation, thereby increasing the recovery period. Sometimes their treatment requires repeated cycles of physical and medical therapy with high cost and resources. For years the prophylactic effect of a prolonged postoperative antiinflammatory therapy against such calcification has been proven.

In a study by Vastel and co-workers (2005), the effect of ketoprofen and celecoxib was compared in the prevention of hip periprosthetic calcification (84). Classification was performed according to the Brooker classification (stage 0-4) and evaluated with an X-ray, for 2 groups of patients treated with both drugs for a period of 7 days after surgery. In both groups, a statistically significant reduction ( $\mathrm{p}=0.014$, Fischer test) of calcification compared to the control group was observed. There were no statistically significant differences between the 2 drug groups. Patient groups were homogeneous, there was no discernible differences in age, sex and underlying disease. Based on the findings from this study, it can be concluded that both drugs can be safely used for prophylaxis of heterotopic hip calcification.

Regarding postoperative osteopenia, in 1996 Fiorentino and co-workers evaluated the efficacy of ketoprofen as prophylaxis using a lower dose than that used as an anti-inflammatory (85). It is known that immobilization leads to a loss of bone mass in both animals and humans. There is an increase in bone resorption and a decrease in its formation. Experiments were performed on rats and osteopenia was induced by tail immobilization and measured at the level of the caudal vertebra and the L2-L4 section by dual-energy X-ray absorptiometry. The caudal vertebra loses bone mineral density (BMD) after tail immobilization. The L2-L4 level does not lose BMD because it is not affected by immobilization. Treatment with ketoprofen was extended for 10 days. The results obtained showed that immobilization only caused bone loss on the caudal vertebra and an increase in the L2-L4 section. Immobilization associated with ketoprofen therapy resulted in decreased bone loss on the caudal vertebra and no change in L2-L4 level. Treatment with ketoprofen without immobilization revealed no differences in BMD. These findings sug- gest that the NSAIDs (ketoprofen in particular) reduce bone resorption and do not significantly alter bone formation.

Orthopaedic patients' postoperative course is characterized by reparative processes that mostly involve the bone. The healing process of fractures and bone defects is characterized by bone tissue regeneration; this phenomenon is due to the stimulation of specific growth factors that act on stromal cells arising from the inflammatory process, and in physiological conditions, may result in the formation of bone matrix.

There is also evidence to suggest that ketoprofen does not seem to interfere with these processes in animal models $(86,87)$. One study compared the effects of ketoprofen with a placebo control group in tibial defects in rats digitally analyzing the bone density up to 21 days after osteotomy (86). In the control group, the optical density increased significantly in relation to time. The same correlation was not observed in the ketoprofen group, as there was a significant increase in optical density during the first week and then a decrease from the twenty-first day onwards.

This study concluded that ketoprofen can be used safely for the first 21 days after surgery. Similar results were reported by Matsumoto et al. (2008) who wanted to compare 48 rats divided into three groups; COX-2 inhibitors versus ketoprofen versus placebo. In this study, histopathologic analysis, immunohistochemical (measuring the expression of COX-2) and histomorphometric of the entire complex (pre-resection zone, zone of resection and post-resection zone) were performed (87). COX-2 was not completely inhibited by celecoxib during the initial phase, but it was active in the central region in all 3 groups.

After 7 days COX-2 was active in the granulation tissue in the control and ketoprofen groups, but not in the celecoxib group. In this group COX-2 was no longer found in the bone marrow after 14 and 21 days, while it was still present in the other 2 groups. Even with these values there were no effects on bone repair. It may be concluded that in the initial phases of inflammation the presence of the enzyme was sufficient for prostaglandins activity be efficient in releasing cells involved in the bone repair process, then, and for this reason, COX-2 inhibitors may be used preferably in the acute phase and for a short period of time. However, for more prolonged therapy, ketoprofen seems safer, due to the fact that it does not inhibit COX-2, even after 21 days. 
Even in the case of bone grafts ketoprofen has been shown to be a safe drug, as demonstrated by a recent study by van Der Heide (88). In this study, which was performed on 27 goats, ketoprofen and meloxicam were not observed to interfere with the integration of a bone graft, either autograft, washed allograft, or allograft, after 7 days of administration. Finally, in another recent pre-clinical study, 30 rabbits were subjected to bilateral posterolateral spinal fusion on a single level using autologous graft harvested from iliac crest (89). This study showed that ketoprofen did not increase the risk of non-union compared with tramadol with a similar rate of fusion (53\%) and non-union (47\%) in both groups.

\section{Cardiovascular diseases}

Cardiovascular (CV) disease is now one of the leading extra-articular causes of morbidity and mortality in RA patients with rheumatic diseases, who show an increased susceptibility to developing cardiac complications. Many studies have shown that coronary artery disease is one of the most common causes of death in RA and seems to occur at a younger age than in the general population (90-92). However, all cardiac structures can be affected during the course of RA (valves, the conduction system, the myocardium, endocardium and pericardium, and the coronary arteries), and cardiac complications include a variety of clinical manifestations such as pericarditis, myocarditis, myocardial fibrosis, arrhythmias, alterations in conduction, coronary diseases and ischemic cardiopathy, valvular disease, pulmonary hypertension and heart failure. Patients with gout not only suffer potentially disabling and deforming arthritic disease, but are also at a high risk for CV and metabolic disorders that includes a multitude of interrelated atherosclerotic risk factors, including abdominal obesity, insulin resistance, atherogenic dyslipidemia, elevated blood pressure, and elevated plasma glucose $(93,94)$. As these are all associated with an unfavourable prognosis, for this reason some patients need an anticoagulant or cardiovascular therapy. In addition, patients undergoing orthopaedic surgery, who are often elderly with associated underlying diseases, are treated with different drugs belonging to different classes, in particular, with oral anticoagulants, which may be affected by the association with NSAIDs.

All NSAIDs, including ketoprofen, should be used with caution in patients treated with anticoagulant and/or antihypertensive drugs. There are several mechanisms by which NSAIDs may increase the likelihood and severity of bleeding in patients treated with warfarin $(95,96)$. Two major types of pharmacokinetic interactions have been reported: 1) displacement of warfarin from plasma albumin and 2) inhibition of the metabolism of warfarin by NSAIDs. In vitro and animal studies on ketoprofen have demonstrated that displacement of warfarin is unlikely to be of clinical significance (97). A placebo-controlled, double-blind study on healthy volunteers, already stabilized on warfarin, treated with ketoprofen (100 mg twice daily for 7 days) demonstrated that ketoprofen did not affect the protrombin time. In particular, there was no change in coagulation cascade parameters and no clinical evidence of bleeding $(24,95)$.

A study on 40 patients with hypertensive disease demonstrated a lack of superiority of nimesulide a preferential COX-2 inhibitor - over ketoprofen, considering the effect on circadian, nocturnal an diurnal mean values of arterial blood pressure. The study clearly indicates that nimesulide is not safer than ketoprofen in the treatment of patients with arterial hypertension since both drugs induced a small increase of arterial blood (98).

Other trials have been conducted with the aim to evaluate the effect of ketoprofen in patients treated with antihypertensive drugs (e.g., captopril or acebutol etc.). The results of these studies showed that ketoprofen does not interfere with blood pressure control or heart rate in hypertensive patients being treated with beta-blockers and diuretics (99), nor affect glomerular filtration rate or blood pressure in essential hypertensive patients treated with a converting enzyme inhibitor such as captopril, suggesting that ketoprofen is a safe choice when short-term treatment with a NSAID is indicated in patients (100).

Another problem in patients receiving NSAIDs could be the increased risk of acute myocardial infarction (AMI). Selective COX-2 inhibitors and non selective COX inhibitors exhibit this undesired effect. Of the non selective COX inhibitors, diclofenac has been shown to have far highest relative risk of developing AMI, whereas ketoprofen is suggested to be safer (101-104). The association between AMI in humans and use of NSAIDs has been demonstrated in several studies, but the mechanisms are still unclear. In an animal model, the interaction of diclofenac and ketoprofen with cardioactive drugs was assessed on the basis of ECG records after the infusion of adrenalin, verapimil or lidocaine to rats treated with diclofenac and ketoprofen versus con- 
trol (105). This study showed no occurrence of cardiotoxic action of diclofenac and ketoprofen in ECG patterns, but diclofenac caused significantly lower sodium plasma concentrations with increased potassium concentrations. These findings may in part explain the increased risk of AMI in patients treated with diclofenac over ketoprofen.

\section{CONCLUSIONS}

In clinical practice, the majority of patients with chronic rheumatic diseases are elderly, suffer from different other diseases such as cardiovascular diseases or metabolic disorders and could be treated with multiple drugs that may interact with NSAIDs. Ketoprofen has been demonstrated to be generally well tolerated in elderly patients, and no interactions with anticoagulant drugs have been observed.

Ketoprofen has been used extensively in the management of all tissue diseases and postoperative pain, it is effective and safe also in patients with acute rheumatic pain, including related bursitis, tendinitis, periarthritis and low back pain, allowing a fast onset of analgesic activity. Efficacy and safety of ketoprofen has been demonstrated by several evidences that underline how ketoprofen is highly effective and compares favourably to other NSAIDs, such as diclofenac or ibuprofen. Ketoprofen is able to provide better analgesic control, greater and faster pain relief with an overall very good tolerability profile. Thus, we can conclude that ketoprofen may represent an optimal choice in the treatment of pain in these patient populations. Ketoprofen has also been proved a valuable molecule useful in various stages in the postoperative course of patients undergoing orthopaedic surgery. Regarding the management of postoperative pain, we can conclude that it may reduce the use or the dose of the opioid drugs, if not fully replace them, thus avoiding the side effects of these therapies. In the postoperative setting, ketoprofen can provide a longer duration of analgesia and a significantly higher overall efficacy when compared to diclofenac. Ketoprofen can be used safely in elastomeric combination without losing its effectiveness and its anti-inflammatory analgesic effect should not be forgotten, often useful in patients with osteo-muscular disorders. Its effectiveness in preventing heterotopic calcification and osteopenia after immobilization has been demonstrated, decreasing in this way the rate of such complications that often delay the functional recovery of the patient. It has been proven to be a safe drug concerning its interaction with bone reparative processes, both in terms of the phenomena of bone regeneration and for the eventual integration of bone grafts that are often used in traumatology.

Based on these clinical evidences, we can conclude that ketoprofen may be a valid treatment option for postoperative pain relief.

\section{Statement of interest \\ Publication of this article was supported by Dom- pé SPA, Italy (unrestricted grant).}

\begin{abstract}
SUMMARY
Ketoprofen is a drug belonging to the family of non-steroidal anti-inflammatory drugs (NSAIDs). The present review examines the main available clinical evidence of ketoprofen in the treatment of acute and chronic pain, of both rheumatic and traumatic origin, as well as postoperative pain. Ketoprofen has shown to be an excellent choice of drug for the treatment of chronic pain in patients with osteoarthritis, rheumatoid arthritis or gout, demonstrating a high level of efficacy with good tolerability also in elderly patients. Even in the treatment of acute forms of pain such as bursitis, tendinitis and back pain, ketoprofen compares favourably to other NSAIDs (e.g., ibuprofen and diclofenac) in terms of efficacy. Ketoprofen has been shown to be effective also for the treatment of post-operative pain, particularly in the orthopaedic field, with an efficacy similar to opioids in some studies. In this setting, some evidence indicates that ketoprofen exhibits additional important benefits, showing to be effective in the prophylaxis of heterotopic calcification following hip or pelvic major intervention, without affecting the bone healing process. Moreover, the use of ketoprofen in elastomeric pump in combination with opioids or other NSAIDs has proven to be effective and safe. In conclusion, available data confirm that ketoprofen is effective and well tolerated, through different administration routes, for the treatment of various forms of rheumatic, traumatic and post-surgical pain, and may therefore be considered as a valid therapeutic option for these patients.
\end{abstract}

Parole chiave - Ketoprofen, NSAID, post-operative pain, rheumatic pain, orthopaedics. Key words - Ketoprofene, FANS, dolore post-operatorio, dolore reumatico, ortopedico. 


\section{REFERENCES}

1. Colvin LA, Lambert DG. Pain medicine: advances in basic sciences and clinical practice. Br J Anaesth 2008; 101: 1-4.

2. Merskey H, Bogduk N (Eds). Classification of chronic pain: descriptions of chronic pain syndromes and definitions of pain terms, 2nd ed. Seattle: IASP Press, 1994.

3. Waddell G, Newton M, Henderson I, Somerville D, Main CJ. A Fear-Avoidance Beliefs Questionnaire (FABQ) and the role of fear-avoidance beliefs in chronic low back pain and disability. Pain 1993; 52: 157-68.

4. Turk DC, Wilson HD. Fear of pain as a prognostic factor in chronic pain: conceptual models, assessment, and treatment implications. Curr Pain Headache Rep. 2010; 14: 88-95.

5. Anderson KO, Green CR, Payne R. Racial and ethnic disparities in pain: causes and consequences of unequal care. J Pain. 2009; 10: 1187-204.

6. Brennan F, Carr BD, Cousins M. Pain Management: A Fundamental Human Right. Anesth Analg 2007; 105: 205-21.

7. The SUPPORT Principal Investigators. A controlled trial to improve care for seriously ill hospitalized patients. JAMA 1995; 274: 1591-8.

8. Dolin SJ, Cashman JN, Bland JM. Effectiveness of acute postoperative pain management. I. Evidence from published data. Br J Anaesth 2002; 89: 409-23.

9. Powell AE, Davies HT, Bannister J, Macrae WA. Rhetoric and reality on acute pain services in the UK: a national postal questionnaire survey. $\mathrm{Br} \mathrm{J}$ Anaesth 2004; 92: 689-93.

10. Manchikanti L, Singh V, Bakhit CE, Fellows B. Interventional techniques in the management of chronic pain: Part 1.0. Pain Physician. 2000; 3: 7-42.

11. Baron R, Binder A, Wasner G. Neuropathic pain: diagnosis, pathophysiological mechanisms and treatment. Lancet Neurol 2010; 9: 807-19.

12. Yunus MB. Fibromyalgia and overlapping disorders: the unifying concept of central sensitivity syndromes. Semin Arthritis Rheum 2007; 36: 339-56.

13. Vlaeyen JW, Crombez G. Fear of movement/(re)injury, avoidance and pain disability in chronic low back pain patients. Man Ther 1999; 4:187-195.

14. Meeus M, Nijs J. Central sensitization: a biopsychosocial explanation for chronic widespread pain in patients with fibromyalgia and chronic fatigue syndrome. Clin Rheumatol 2007; 26: 465-73.

15. Staud R. Evidence of involvement of central neural mechanisms in generating FM pain. Curr Rheumatol Rep 2002; 4: 299-305.

16. Leung L, Cahill CM. TNF-a and neuropathic pain - a review. J Neuroinflammation 2010; 7: 27.

17. Ji R, Gereau RW, Malcangio M, Strichartz GR. MAP kinase and pain. Brain Res Rev 2009; 60: 135-48.

18. Bradesi S. Role of spinal cord glia in the central processing of peripheral pain perception. Neurogastroenterol Motil. 2010; 22: 499-511.
19. Roditi D, Waxenberg L, Robinson ME. Frequency and perceived effectiveness of coping define important subgroups of patients with chronic pain. Clin J Pain 2010; 26: 677-82.

20. McCormack KJ, Brune K. Dissociation between the anti-nociceptive and anti-inflammatory effects of the nonsteroidal anti-inflammatory drugs: a survey of their analgesic efficacy. Drugs 1991; 41: 533-47.

21. Barbanoj MJ, Antonijoan RM, Gich I. Clinical pharmacokinetics of dexketoprofen. Clin Pharmacokinet 2001; 40: 245-62.

22. Cabré F, Fernández MF, Calvo L, Ferrer X, García ML, Mauleón D. Analgesic, antiinflammatory, and antipyretic effects of S(+)-ketoprofen in vivo. J Clin Pharmacol 1998; 38: 3S-10S.

23. Panerai A. [Symptoms of pain] Torino: Edizioni Minerva Medica, 1999.

24. Marmo E, Ottavo R, Giordano L, Paone G, Falcone O, Spaziante G, et al. Experimental assessment of some pharmacodynamic features of ketoprofen lysine. Pain relief activity, antipyretic effects, anti-inflammatory activity, anti-platelet aggregation activity and interference with the biosynthesis of prostaglandins. Torino, Arch Sci Med 1980; 137: 387-404.

25. Natale, et al. Studio in soggetti volontari sani della biodisponibilità relativa e della farmacocinetica di ketoprofen dopo somministrazione per via orale sotto forma di sale di lisina in formulazione bustine di granulato (dose singola e ripetuta) e in forma di ketoprofen acido formulato in capsule. Data on file 1991.

26. Rusca et al. Two way crossover, randomised, single dose comparative bioavailability study of ketoprofen lysine salt as $8 \%$ drop solution versus ketoprofen as capsules $50 \mathrm{mg}$ (Orudis ${ }^{\circledR}$ ) after oral administration to healthy volunteers of both sexes. (IPAS-KETO-02594), data on file 1994.

27. D'arienzo M. Pennisi M, Zanolo G, Borsa M. Ketoprofen lysine: ketoprofen serum levels and analgesic activity. Drugs Exp Clin Res 1984; 10: 863-6.

28. Veys EM. 20 Years' Experience with ketoprofen. Scan J Rheumatol 1991; 90: 3-44.

29. Walker JL. Interrelationships of SRS-A production and arachidonic acid metabolism in human lung tissue. Adv Prostaglandin Thromboxane Res 1980; 6: 115-9.

30. Díaz-Reval MI, Ventura-Martínez R, Déciga-Campos M, Terrón JA, Cabré F, López-Muñoz FJ. Evidence for a central mechanism of action of S-(+)-ketoprofen. Eur J Pharmacol 2004; 483: 241-8.

31. Björkman R. Central antinociceptive effects of nonsteroidal anti-inflammatory drugs and paracetamol: experimental studies in the rat. Acta Anaesthesiol Scand Suppl 1995; 103: 1-44.

32. Ossipov MH, Jerussi TP, Ren K, Sun H, Porreca F. Differential effects of spinal (R)-ketoprofen and (S)ketoprofen against signs of neuropathic pain and tonic nociception: evidence for a novel mechanism of action of (R)-ketoprofen against tactile allodynia. Pain 2000; 87: 193-9. 
33. Kokki H, Karvinen M, Jekunen A. Diffusion of ketoprofen into the cerebrospinal fluid of young children. Paediatr Anaesth 2002; 12: 313-6.

34. Kubota T, Komatsu H, Kawamoto H, Yamada T. Studies on the effects of anti-inflammatory action of benzoyl-hydrotropic acid (ketoprofen) and other drugs, with special reference to prostaglandin synthesis. Arch Int Pharmacodyn Ther 1979; 237: 169-76.

35. Kantor TG. Ketoprofen: a review of its pharmacologic and clinical properties. Pharmacotherapy 1986; 6: 93-103.

36. Dieppe PA, Lohmander LS. Pathogenesis and management of pain in osteoarthritis. Lancet 2005; 365 : 965-73.

37. Carrabba M, Sarzi-Puttini P. Osteoarthritis in the third millennium: a new era for an old disease? Seminars Arthritis Rheum 2005; 34: 1-2.

38. Pritzker K. Pathology of osteoarthritis. In: Brandt K, Doherty M, Lohmander LS, eds. Osteoarthritis, 2nd edn. Oxford: Oxford University Press, 2003: 49-58.

39. Watt I, Doherty M. Plain radiographic features of osteoarthritis. In: Brandt K, Doherty M, Lohmander LS, eds. Osteoarthritis, 2nd edn. Oxford: Oxford University Press, 2003: 211-25.

40. Linaker CH, Walker-Bone K, Palmer K, Cooper C. Frequency and impact of regional musculoskeletal disorders. Baillieres Best Pract Res Clin Rheumatol 1999; 13: 197-215.

41. McCrae F, Shouls J, Dieppe P, Watt I. Scintigraphic assessment of osteoarthritis of the knee joint. Ann Rheum Dis 1992; 51: 938-42.

42. Creamer P, Hunt M, Dieppe P. Pain mechanisms in osteoarthritis of the knee: effect of intraarticular anesthetic. J Rheumatol 1996; 23: 1031-6.

43. Farrell M, Gibson S, McMeeken J, Helme R. Pain and hyperalgesia in osteoarthritis of the hands. J Rheumatol 2000; 27: 441-7.

44. Marcolongo R, Canesi B, Ferri S, Oriente P, Perpignano G, Serni U, et al. Efficacy and tolerability of ketoprofen $200 \mathrm{mg}$ controlled-release cps vs indomethacin $50 \mathrm{mg}$ cps in patients with symptomatic hip osteoarthritis. A multicentre study. Minerva Med 1997; 88: 383-91.

45. Chevallard M, Mele G, Borsa M, Malandrino S, Tonon GC, Carrabba M. Effectiveness and tolerability of ketoprofen lysine, a once a day, in patients with rheumatic disorders. Drugs Exptl Clin Res 1987; 13: 293-6.

46. Torri G, Cecchettin M, Bellometti S, Galzigna L. Analgesic effect and beta-endorphin and substance $\mathrm{P}$ levels in plasma after short-term administration of a ketoprofen-lysine salt or acetylsalicylic acid in patients with osteoarthrosis. Curr Ther Res 1995; 56: 62-9.

47. Sarzi-Puttini P, Atzeni F. Rheumatoid arthritis from the clinical perspective. Reumatismo 2004; 3: 22-5.

48. Combe R. Early rheumatoid arthritis: strategies for prevention and management. Best Practice \& Research Clinical Rheumatology 2007; 21: 27-42.

49. Guillemin F, Suurmeijer T, Krol B, Bombardier C,
Briançon S, Doeglas D, et al. Functional disability in early rheumatoid arthritis: description and risk factors. J Rheumatol 1994; 21: 1051-5.

50. Wienecke T, Gotzsche PC. Paracetamol versus nonsteroidal anti-inflammatory drugs for rheumatoid arthritis. Cochrane Database Syst Rev 2004; 1: CD003789.

51. Carrabba M, Chevallard M, Mele G, Borsa M, Malandrino S, Tonon GC. Ketoprofen lysine in rheumatoid arthritis: efficacy and tolerability of two therapeutic schedules with evaluation of synovial prostaglandin levels. Current Ther Res 1987; 42: 70-6.

52. Schattenkirchner M. Long-term safety of ketoprofen in an elderly population of arthritic patients. Scand J Rheumatol 1991; 91: 27-36.

53. Le Loet X. Safety of ketoprofen in the elderly: a prospective study on 20,000 patients. Scand J Rheumatol 1991; 18: 21-7.

54. Bieber JD, Terkeltaub RA. Gout: on the brink of novel therapeutic options for an ancient disease. Arthritis Rheum 2004; 50: 2400-14.

55. Teng GG, Nair R, Saag KG. Pathophysiology, clinical presentation and treatment of gout drugs. 2006; 66 : 1547-63.

56. Richette P, Bardin T. Gout. Lancet 2010; 375: 318-28.

57. Roddy E, Zhang W, Doherty M. The changing epidemiology of gout. Nat Clin Pract Rheumatol 2007; 3: 443-9.

58. Zhang W, Doherty M, Bardin T, Pascual E, Barskova V, Conaghan P, et al. EULAR Standing Committee for International Clinical Studies Including Therapeutics. EULAR evidence based recommendations for gout. Part II: Management. Report of a task force of the EULAR Standing Committee for International Clinical Studies Including Therapeutics (ESCISIT). Ann Rheum Dis 2006; 65: 1312-24.

59. Schlesinger N, Detry MA, Holland BK, Baker DG, Beutler AM, Rull M. Local ice therapy during bouts of acute gouty arthritis. J Rheumatol 2002; 29: 331-4.

60. Schlesinger N, Schumacher R, Catton M, Maxwell L. Colchicine for acute gout. Cochrane Database Syst Rev 2006; 4: CD006190.

61. Sutaria S, Katbamna R, Underwood M. Effectiveness of interventions for the treatment of acute and prevention of recurrent gout - a systematic review. Rheumatology (Oxford) 2006; 45: 1422-31.

62. Siegmuth W, Placheta O. Double-blind trial: ketoprofen versus phenylbutazone in acute gouty arthritis (German). Wien Klin Wochenschr 1976; 88: 535-9.

63. Cobra CJ, Cobra J. Comparative study of ketoprofen and penylbutazone in gout attacks (French). Rumatologie; 1980; 47: 141-6.

64. Altman RD, Honig S, Levin JM, Lightfoot RW. Ketoprofen versus indomethacin in patients with acute gouty arthritis: a multicenter, double blind comparative study. J Rheumatol 1988; 15: 1422-6.

65. Biundo JJ Jr, Mipro RC Jr, Fahey P. Sports-related and other soft-tissue injuries, tendinitis, bursitis, and occupation-related syndromes. Curr Opin Rheumatol 1997; 9: 151-4. 
66. Biundo JJ, Irwin RW, Umpierre E. Sports and other soft tissue injuries, tendinitis, bursitis, and occupation-related syndromes. Curr Opin Rheumatol 2001; 13: 146-9.

67. Wilson JJ, Best TM. Common overuse tendon problems: A review and recommendations for treatment. Am Fam Physician 2005; 72: 811-8.

68. Fatti, et al. Valutazione dell'efficacia e tollerabilità di ketoprofen sale di lisina in formulazione in bustine per uso orale in pazienti con affezioni flogistiche dell'apparato muscolo-scheletrico (Reumatismo extra-articolare) studio doppio cieco comparativo a placebo. Data on file, 1991. Evaluation of the effectiveness and tolerability of ketoprofen lysine salt formulation in sachets for oral use in patients with inflammatory diseases of the musculo-skeletal system (extra-articular rheumatism), double-blind study compared with placebo.

69. Jokhio IA, Siddiqui KA, Waraich T, Abbas M, Ali A. Study of efficacy and tolerance of ketoprofen and diclofenac sodium in the treatment of acute rheumatic and traumatic conditions. J Pak Med Assoc 1998; 48: 373-6.

70. Robbins D, Taylor MAH, Brown MD, McIlwain H. Ketoprofen versus ibuprofen for acute sports injuries: are there differences between nonsteroidal anti-inflammatory drugs? Curr Ther Res 1990; 48: 780-9.

71. Chou R. Pharmacological management of low back pain. Drugs 2010; 70: 387-402.

72. Chou R. Diagnosis and treatment of low back pain: a joint clinical practice guideline from the american college of physicians and the american pain society. Ann Intern Med. 2007; 147: 478-91.

73. Van Tulder. European guidelines for the management of acute nonspecific low back pain in primary care. Eur Spine J 2006; 15: S169-91.

74. Roelofs PD, Deyo RA, Koes BW, Scholten RJ, van Tulder MW. Nonsteroidal anti-inflammatory drugs for low back pain: an updated Cochrane review. Spine (Phila Pa 1976) 2008; 33: 1766-74.

75. Levernieux J, Beaslay N, Seze S. Comparative study between injectable ketoprofen and indometacine in the treatment of lomboradicular pain. Revue Internationale de rhumatologie 1986; 16: 171-5.

76. Matsumo S, Kaneda K, Norhara Y. Clinical evaluation of ketoprofen (Orudis) in lumbago - a doubleblind comparison with diclofenac sodium. Br J Clin Pract 1981; 35: 266.

77. Castagnera L, Vital JM, Macouillard G, Destribats B, Esposito J, Harrewyn JM. Study of the analgesic effectiveness of intravenous ketoprofen in orthopedic surgery. Sem Hop Paris 1988; 32: 2179-82.

78. Manani G, Corliano L, Zanette G, Pizzali M, Borreggine D, Calzigna L. Ketoprofen and Naproxen in acute postoperative orthopedic pain. Acta Anaesth Italica 1993; 44: 73-80.

79. Shah S, Soomro M, Kella U, Talpur A, Dino Dal W. Comparative study of non steroidal anti inflammatory drugs in postoperative pain. J Surg Pak Dec 2003; 8: 2-5.
80. Karvonen S, Salomaki T, Olkkola T. Efficacy of oral Paracetamol and Ketoprofen for pain management after measure orthopedic surgery. Methods Find Exp Clin Pharmacol 2008; 30: 703-6.

81. Anacardio R, Bartolini S, Gentile MM, Bagnasco M, Carlucci G. HPLC investigated physicochemical compatibility between Artrosilene injectable solution and other pharmaceutical products frequently used for combined therapy into elastomeric Baxter LV5 infusion devices. Int J Immunopathol Pharmacol 2005; 18 : 791-8.

82. Langlais F, Bourgin T, Maignan JM, Sauvage J, Harrewyn JM. Comparative study of ketoprofen and pethidine in severe postoperative pain. Ann Fr Anesth Reanim 1987; 6: 408-12.

83. Hommeril JL, Bernard JM, Gouin F, Pinaud M. Ketoprofen for pain after hip and knee arthroplasty. $\mathrm{Br}$ J Anaesth 1994; 72: 383-7.

84. Vastel L, Rosencher N, Siney H, Courpied JP. Prevention of heterotopic ossifications in hip arthroplasty: effectiveness of selective Cox-2 inhibitors (celecoxib) versus ketoprofen. Rev Chir Orthop Reparatrice Appar Mot 2005; 91: 64-9.

85. Fiorentino S, Melillo G, Fedele G, Clavenna G, D'Agostino C, Mainetti E, et al. Ketoprofen lysine salt inhibits disuse-induced osteopenia in a new non-traumatic immobilization model in the rat. Pharmacol Res 1996; 33: 277-81.

86. Martins MV, da Silva MA, Medici Filho E, de Moraes LC, Castilho JC, da Rocha RF. Evaluation of digital optical density of bone repair in rats medicated with ketoprofen. Braz Dent J 2005; 16: 207-12.

87. Matsumoto MA, De Oliveira A, Ribeiro Junior PD, Nary Filho H, Ribeiro DA. Short-term administration of non-selective and selective COX-2 NSAIDs do not interfere with bone repair in rats. J Mol Histol 2008; 39: 381-7.

88. van der Heide HJ, Hannink G, Buma P, Schreurs BW. No effect of ketoprofen and meloxicam on bone graft ingrowth: a bone chamber study in goats. Acta Orthop 2008; 79: 548-54.

89. Urrutia J, Mardones R, Quezada F. The effect of ketoprophen on lumbar spinal fusion healing in a rabbit model. Laboratory investigation. J Neurosurg Spine 2007; 7: 631-6.

90. Del Rincon I, Williams K, Stern MP, Freeman GL, Escalante A. High incidence of cardiovascular events in a rheumatoid arthritis cohort not explained by traditional cardiac risk factors. Arthritis Rheum 2001; 44: 2737-45.

91. Solomon DH, Karlson EW, Rimm EB, Cannuscio CC, Mandl LA, Manson JE, et al. Cardiovascular morbidity and mortality in women diagnosed with rheumatoid arthritis. Circulation 2003; 107: 1303-7.

92. Maradit-Kremers H, Nicola PJ, Crowson CS, Ballman KV, Gabriel SE. Cardiovascular death in rheumatoid arthritis: a population-based study. Arthritis Rheum 2005; 52: 722-32.

93. Lee J, Sparrow D, Vokonas PS, Landsberg L, Weiss ST. Uric acid and coronary heart disease risk: evi- 
dence for a role of uric acid in the obesity-insulin resistance syndrome. The Normative Aging Study. Am J Epidemiol 1995; 142: 288-94.

94. Choi HK, Curhan G. Independent impact of gout on mortality and risk for coronary heart disease. Circulation 2007; 116: 894-900.

95. McElnay JC, D’Arcy PF. Displacement of albuminbound warfarin by anti-inflammatory agents in vitro. J Pharm Pharmacol 1980; 32: 709-11.

96. Sancilio LF, Taylor MA, Mathur PP, Crowe JT. Interaction between warfarin and nonsteroidal anti-inflammatory drugs (NSAIDs) in rats. Life Sci 1985; 36: 1041-50.

97. Mieszczak C, Winther K. Lack of interaction of ketoprofen with warfarin. Eur J Clin Pharmacol 1993; 44: 205-6.

98. Saran T, Sodolski W, Sodolska K, Danilkiewicz WC, Schabowski J. Effect of nimesulide-a preferential COX-2 inhibitor on arterial blood pressure, compared to ketoprofen. Ann Univ Mariae Curie Sklodowska Med 2004; 59: 261-7.

99. Weiss Y, Chenard A, De Kermadec JM, Tertrain F, Abiteboul M. Maintenance of blood pressure control in elderly hypertensives on ketoprofen. Scand J Rheumatol Suppl 1991; 91: 37-44.
100. Cusson JR, du Souich P, Le Morvan P, Thibault G, Phillips R, Milot A, et al. Effect of ketoprofen on blood pressure, endocrine and renal responses to chronic dosing with captopril in patients with essential hypertension. Blood Press 1992; 1: 162-7.

101. McGettigan P, Henry D. Cardiovascular risk and inhibition of cyclooxygenase: a systemic review of the selective and nonselective inhibitors of cyclooxygenase. JAMA 2006; 296: 1633-44.

102. Ray WA, Stein CM, Hall K. Daugherty JR, Griffin MR. Non steroidal anti-inflammatory drugs and risk of serious coronary heart disease; an observational cohort. Lancet 2002; 359: 118-23.

103. Andersohn F. Use of first and second-generation cyclooxygenase-2-selective nonsteroidal anti-inflammatory drugs and risk of acute myocardial infarction. Circulation 2006; 113: 1950-7.

104. Singh G, Wu O, Ranghorne P, Madhok R. Risk of acute myocardial infarction with non-steroidal anti-inflammatory drugs: a meta-analysis. Arthritis Res Ther 2006; 8: 153-8.

105. Jakovljevic V, Sabo A, Tomić Z, Milijasević B, Popovic M, Vasovic V, et al. Interaction of diclofenac and ketoprofen with cardioactive drugs in rats. Eur J Drug Metab Pharmacokinet 2009; 34: 11-7. 